\title{
Simultaneous Observations of Jupiter on Three Frequencies
}

\author{
I. Kazes ${ }^{1}$ \\ Årecibo Ionospheric Observatory, Ârecibo, Puerto Rico ${ }^{2}$
}

The planet Jupiter was observed at $41.7 \mathrm{Mc} / \mathrm{s}, 195$ $\mathrm{Mc} / \mathrm{s}$, and $430 \mathrm{Mc} / \mathrm{s}$ during the month of September 1964 at the Arecibo Ionospheric Observatory [Gordon and Lalonde, 1961]. Each feed consisted of a pair of folded dipoles with reflectors separated by one-half wavelength. The three systems of feed were installed under carriage house No. 2 and centered approximately along a radius of the spherical reflector. The 195$\mathrm{Mc} / \mathrm{s}$ and $430-\mathrm{Mc} / \mathrm{s}$ feeds were centered to better than $5 \mathrm{~min}$ of arc. With respect to the $430-\mathrm{Mc} / \mathrm{s}$ dipoles, the $41.7-\mathrm{Mc} / \mathrm{s}$ dipoles were parallel while the $195-\mathrm{Mc} / \mathrm{s}$ dipoles were perpendicular. The illumination of the surface corresponds to a beam width of $18 \mathrm{~min}$ of arc at $430 \mathrm{Mc} / \mathrm{s}, 37 \mathrm{~min}$ of are at $195 \mathrm{Mc} / \mathrm{s}$, and approximately $2^{\circ}$ at $41.7 \mathrm{Mc} / \mathrm{s}$.

The motion of the planet through the beam agreed to $\pm 2 \mathrm{~min}$ of arc with that predicated from the ephemerides. The whole region was later surveyed and no source stronger than 10 percent of the flux of Jupiter was observed. Furthermore, on 12 November 1964 with Jupiter completely out of the beam, the beam was again pointed at the position of 15 September 1964 and again no confusing source was observed. Altogether more than 30 drift curves and declination scans of Jupiter were taken; of this number only 26 observations exist at all three frequencies simultaneously. For these observations to within $10^{\circ}$, the $41.7-\mathrm{Mc} / \mathrm{s}$ dipoles as well as the $430-\mathrm{Mc} / \mathrm{s}$ dipoles were oriented east-west, while the 195-Mc/s dipoles were oriented north-south. ${ }^{3}$

Whenever Jupiter was observed, the nearest radio source 3 C79 was also observed for calibration. The fluxes assumed for $3 \mathrm{C} 79$ were $70 . \times 10^{-26} \mathrm{Wm}^{-2}(\mathrm{c} / \mathrm{s})^{-1}$ at $41.7 \mathrm{Mc} / \mathrm{s}, 25 . \times 10^{-26} \mathrm{Wm}^{-2} \mathrm{c} / \mathrm{s}^{-1}$ at $195 \mathrm{Mc} / \mathrm{s}$, and 13. $\times 10^{-26} \mathrm{~W} \mathrm{~m}^{-2}(\mathrm{c} / \mathrm{s})^{-1}$ at $430 \mathrm{Mc} / \mathrm{s}$. The antenna temperature of Jupiter for each day was converted into flux using the antenna temperature of $3 \mathrm{C} 79$ measured the same day. All fluxes were then normalized to the standard distance corresponding to a semipolar diameter of $22.75^{\prime \prime}$.

\footnotetext{
On leave from Meudon Observatory - France.

2 The Arecibo Ionospheric Observatory is operated by Cornell University with the sup port of the Advanced Research Projects Agency under a research contract with the Air Force Office of Scientific Research.

${ }^{3}$ In September 1964. Jupiter's declination varied very closely around $18^{\circ}$ which is approximately the latitude of the site at the AIO.
}

The mean value and the observed rms deviation are as follows:

$$
\begin{aligned}
& S_{430}=(7.2 \pm 1.6) 10^{-26} \mathrm{Wm}^{-2}(\mathrm{c} / \mathrm{s})^{-1} \\
& S_{195}=(6.2 \pm 0.7) 10^{-26} \mathrm{Wm}^{-2}(\mathrm{c} / \mathrm{s})^{-1} \\
& S_{41.7} \leqslant(35 .) 10^{-26} \mathrm{Wm}^{-2}(\mathrm{c} / \mathrm{s})^{-1} .
\end{aligned}
$$

During the 15 to $20 \mathrm{~min}$ of each observation, there was no activity equal to or greater than $35 . \times 10^{-26}$ $\mathrm{W} \mathrm{m}^{-2}(\mathrm{c} / \mathrm{s})^{-1}$ recorded at $41.7 \mathrm{Mc} / \mathrm{s}$ although on some occasions System III radio longitude of the central meridian of Jupiter was favorable for decametric activity.

For comparison with the observed rms deviations of 22 and 11 percent on the flux at $430 \mathrm{Mc} / \mathrm{s}$ and $195 \mathrm{Mc} / \mathrm{s}$ respectively, we estimated the errors due to calibration and to signal-to-noise ratio. The total errors are 13 percent at $430 \mathrm{Mc} / \mathrm{s}$ and 8 percent at $195 \mathrm{Mc} / \mathrm{s}$. These results suggest a variation of the flux of Jupiter which is smaller at the lower frequency. An analysis of the flux plotted against System III longitude ( $\lambda$ III) shows that the best fit for both frequencies would be periodic rather than linear (fig. 1).

Furthermore, to investigate the apparent existence of a relation between the variations of the fluxes at the two frequencies, the correlation coefficient has been calculated for simultaneous observations only. The value of this coefficient is equal to 0.5 . The correlation coefficient calculated in the same way for the variations of $3 \mathrm{C} 79$ is equal to -0.3 .

After the discovery of the polarization of the planetary emission [Radhakrishnan and Roberts, 1960] most of the variations of Jupiter's flux, from about 10 to $30 \mathrm{~cm}$ of wavelength reported have been attributed to the rotation of the planet [Mc Clain, 1959; McClain and Sloanaker, 1959; Sloanaker, 1959; Sloanaker and Boland, 1961; Mc Clain, Nichols, and Waak, 1960; Morris and Bartlett, 1963; Morris and Berge, 1962] which causes the plane of polarization to rock through $\pm 9^{\circ}$ [Morris and Berge, 1962]. While the thermal emission (for $\lambda<10 \mathrm{~cm}$ ) is expected to be unpolarized and come from the visible disk of the planet, the nonthermal, approximately flat spectrum emission (for $\lambda<10 \mathrm{~cm}$ ) is polarized and comes from an elliptical source [Morris and Berge, 1962]. In 
addition, the suggestion of a beaming effect has been pointed out [Morris and Berge, 1962]. The beaming [Gary, 1963; Bash, Drake, Gundermann, and Heiles, 1964] of the radiation which manifests itself as a variation of the total intensity as the planet rotates, is now unambiguously demonstrated [Roberts and Komesaroff, 1964].

Furthermore, it has been shown [Berge and Morris, 1964; Roberts and Komesaroff, 1964] that there is a physical displacement of the emitting region due to a displacement of the magnetic dipole from the center of the planet.

If the variation described at $430 \mathrm{Mc} / \mathrm{s}$ and 195 $\mathrm{Mc} / \mathrm{s}$ have the same origin, then the linearly polarized wave should be affected by Faraday rotation in the ionosphere. A preliminary analysis of figure 1 suggests cyclic variations in particular from $\lambda$ III $=0$ to $\lambda \mathrm{III}=200^{\circ}$. When limited to this range of longitudes, the calculated correlation coefficient for simultaneous observations at the two frequencies is 0.6. This number suggests that the variations of Jupiter's flux at $195 \mathrm{Mc} / \mathrm{s}$ and $430 \mathrm{Mc} / \mathrm{s}$ are reasonably well in phase. On the other hand the phase of a variation is a function of the position angle $\theta$ of the $E$ plane of the dipole diminished by the effect of Faraday rotation $\varphi$. Considering that the variations are in phase, we can write.

$$
\begin{aligned}
& (\theta-\varphi)_{430}=(\theta-\varphi)_{195} \text { with } \varphi_{195}=\varphi_{430}\left(\frac{430}{195}\right)^{2}, \\
& \theta_{430}=90^{\circ} \text { and } \theta_{195}=180^{\circ} . \text { Then } \varphi_{430} \cong 23^{\circ} .
\end{aligned}
$$
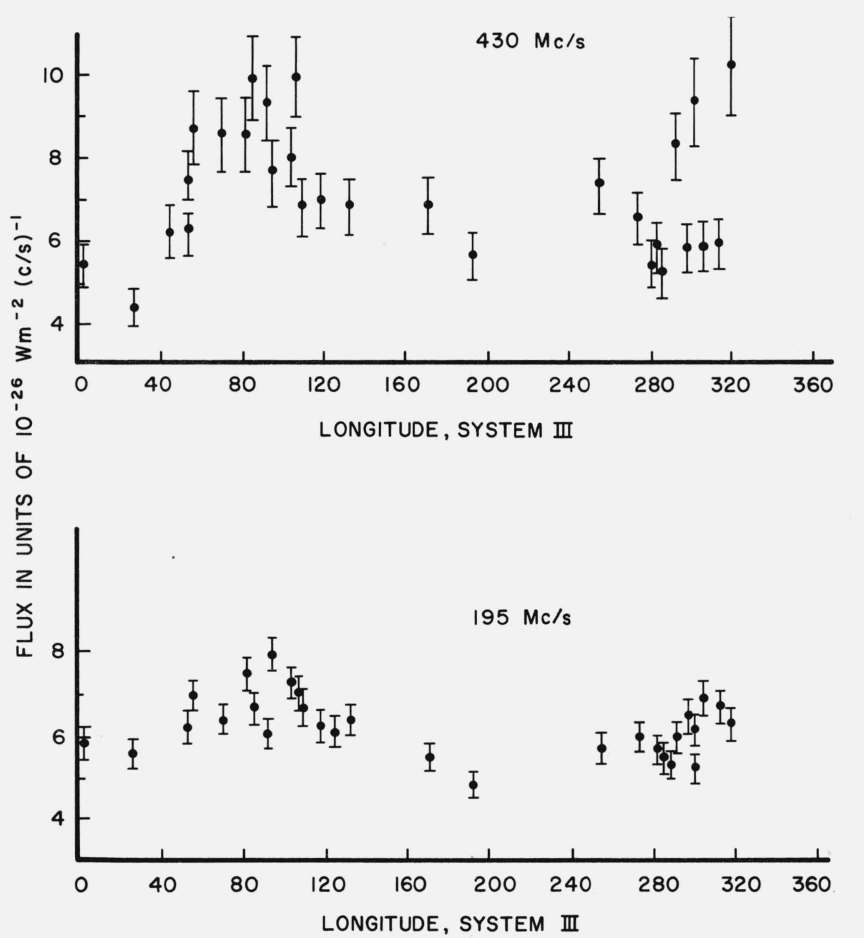

FigURE 1. Flux density at $430 \mathrm{Mc} / \mathrm{s}$ and $200 \mathrm{Mc} / \mathrm{s}$ plotted against System III longitude.
The values of $\theta$ are only known to $\pm 5^{\circ}$ since the $430-\mathrm{Mc} / \mathrm{s}$ and $195-\mathrm{Mc} / \mathrm{s}$ dipoles were not always exactly east-west and north-south respectively. The perpendicularity of the two sets of dipoles could be off by $5^{\circ}$ due to construction inaccuracy.

According to a recent paper [Lawrence, Little and Chivers, 1964], the Faraday rotation at $100 \mathrm{Mc} / \mathrm{s}$ is typically $6.6 \mathrm{rad}$. With this result the corresponding rotations in degrees at $430 \mathrm{Mc} / \mathrm{s}$ and $195 \mathrm{Mc} / \mathrm{s}$ are approximately $20^{\circ}$ and $98^{\circ}$ respectively. Furthermore observations on polarization of the galactic $75-\mathrm{cm}$ radiation [Van de Hulst, 1961] suggest possible Faraday rotation in the ionosphere of $10^{\circ}$ to $20^{\circ}$ in the middle of the night. Finally, the measurements of Faraday rotation made at the AIO by radar means [Morgan, 1965] on $430 \mathrm{Mc} / \mathrm{s}$ in September 1964 between 11:00 and 16:00 AST give values between 50 and 90 deg. round trip. The probability is highest around 60 to $70 \mathrm{deg}$. A one-way transit of the ionosphere would thus give about $35 \pm 10 \mathrm{deg}$. Since the observations described in this paper have been made between 03:00 and 06:00 AST, it is reasonable to adopt a value of $25^{\circ}$ rotation at $430 \mathrm{Mc} / \mathrm{s}$ and $120^{\circ}$ at $195 \mathrm{Mc} / \mathrm{s}$.

If the given interpretation is correct, there is an experimental evidence to consider that the polarized Jovian decimeter radiation extends until a wavelength of at least $1.5 \mathrm{~m}$. Furthermore, from observations at two or more frequencies, a reasonably good value of the Faraday rotation can be given.

Further analysis of figure 1 shows that the relative variations of the E-W flux at $430 \mathrm{Mc} / \mathrm{s}$ are more important than those of the N-S flux at $195 \mathrm{Mc} / \mathrm{s}$. This difference could be explained supposing that the observed $430-\mathrm{Mc} / \mathrm{s}$ radiation comes in particular from the highly polarized equatorial region while the observed $195-\mathrm{Mc} / \mathrm{s}$ radiation is supposed to be the contribution of the polarized component in a direction perpendicular to the equator of the planet.

This supposition can only be true if the Jovian emission at $430 \mathrm{Mc} / \mathrm{s}$ and $195 \mathrm{Mc} / \mathrm{s}$ have the same origin as that observed in the range of $3000 \mathrm{Mc} / \mathrm{s}$ to $960 \mathrm{Mc} / \mathrm{s}$ by other observers,

In similar conditions, though not simultaneously, [Gary, 1963] observed the E-W and N-S flux of Jupiter at $1400 \mathrm{Mc} / \mathrm{s}$. When a comparison is made between the E-W flux at $1400 \mathrm{Mc} / \mathrm{s}$ to the E-W flux at $430 \mathrm{Mc} / \mathrm{s}$ and between the N-S flux at $1400 \mathrm{Mc} / \mathrm{s}$ to the N-S flux at $195 \mathrm{Mc} / \mathrm{s}$ it follows that there exist mean flux differences of the order of 7 to 10 percent; also the observed variations at $430 \mathrm{Mc} / \mathrm{s}$ and $195 \mathrm{Mc} / \mathrm{s}$ can be as great as twice or more the corresponding variations at $1400 \mathrm{Mc} / \mathrm{s}$. The differences in mean flux could be mainly due to the use of different calibration sources. The differences in the variations could be explained by the beaming of the radiation of the Jovian $\mathrm{V}$ an Allen belts. The beaming will have a certain influence on the fractional polarization as well as on the total flux. Hence it will be difficult to establish a variability of Jupiter's decimeter radiation with frequency unless more simultaneous observations are made at as many frequencies as possible. 


\section{References}

Bash, F. N., F. D. Drake, E. Gundermann, and C. E. Heiles (1964), 10-CM observations of Jupiter, 1961, 1963, Astrophys. J. 139, No. 3, 975-985.

Berge, G. L., and D. Morris (1964), Decimeter Measurements relating to the possible displacement of Jupiter's magnetic dipole, Astrophys. J. 140, No. 3, 1330-1332.

Gary, B. L. (1963), An investigation of Jupiter's $1400 \mathrm{Mc} / \mathrm{sec}$ radiation, Astron. J. 68, No. 8, 568-572.

Gordon, W. E., and L. M. Lalonde (1961), The Design and capabilities of an ionospheric radar probe, IRE Trans. Ant. Prop. AP-9, No. $1,17-22$.

Lawrence, R. S., C. G. Little, and H. J. A. Chivers (1964), A survey of ionospheric effects upon earth-space radio propagation, Proc. IEEE 52, No. 1, 4-27.

McClain, E. F. (1959), A test for non-thermal radiation from Jupiter at a wavelength of $21 \mathrm{~cm}$, Astron. J. 64, 339-340.

Mc Clain, E. F., J. H. Nichols, and J. A. Waak (1960), Possible variations in the centimeter wave emission from Jupiter, Paper presented at the 13th General Assembly of URSI London.

McClain, E. F., and R. M. Sloanaker (1959), Preliminary observations at $10-\mathrm{cm}$ wavelength using the NRL 84-foot radio telescope, Proc. IAU-URSI Paris Symposium on Radio Astronomy 61, ed. R. N. Bracewell (Stanford Univ. Press, Stanford, Calif.).
Morgan, G. (1965), Cornell University, Research Report (in press).

Morris, D., and J. F. Bartlett (1963), Polarization of the $2840 \mathrm{Mc} / \mathrm{s}$ radiation from Jupiter, Mem. Soc. Roy. Sci. Liege 7, 564-568.

Morris, D., and G. L. Berge (1962), Measurements of the polarization from Jupiter, Astrophys. J. 136, 276-282.

Radhakrishnan, V., and J. A. Roberts (1960), Polarization and angular extent of the $960 \mathrm{Mc} / \mathrm{s}$ radiation from Jupiter, Phys. Rev. Letters 4, 493-494.

Roberts, J. A., and M. M. Komesaroff (1964), Evidence for asymmetry of Jupiter's Van Allen belt, Nature 203, No. 4947, 827-830.

Sloanaker, R. M. (1959), Apparent temperature of Jupiter at a Wavelength of $10 \mathrm{~cm}$, Astron. J. 64, 346.

Sloanaker, R. M., and J. W. Boland (1961), Observations of Jupiter at a wavelength of $10 \mathrm{~cm}$, Astrophys. J. 133, 649-656.

Van de Hulst, H. C. (1961), Polarisatie van de Radiostraling ven het Melkwegstelsel, Versl. Afd. Naturk. Kon. Ned. Ak. Wet. Amsterdam 70, No. 2, 23-27.

\section{A Report of Measurements}

\section{Barber ${ }^{1}$ and J. F. R. Gower ${ }^{2}$}

Summary: The main results are values of the flux density for Jupiter at $610 \mathrm{Mc} / \mathrm{s}$ (normalized to 4.04 A.U.):

Flux density $=6.6 \pm 0.3 \times 10^{-26} \mathrm{Wm}^{-2}(\mathrm{c} / \mathrm{s})^{-1}$ at $610 \mathrm{Mc} / \mathrm{s}$

Flux density $=5.1 \pm 0.8 \times 10^{-26} \mathrm{Wm}^{-2}(\mathrm{c} / \mathrm{s})^{-1}$ at $178 \mathrm{Mc} / \mathrm{s}$.

\footnotetext{
${ }^{1}$ Royal Radar Establishment, Ministry of Aviation, Great Malvern, England.

${ }^{2}$ Mullard Radio Astronomy Observatory, Cavendish Laboratory, Cambridge, England.
}

(Paper 69D12-592) 